\title{
EDITORIAL
}

\section{Excited to be Editor-in-Chief for Powder Diffraction}

With the new year Tom Blanton has stepped down as the interim Editor-in-Chief (EiC) of Powder Diffraction. Tom did a superb job during his tenure that included taking over for Ting Huang and bringing to press the four regular issues and two supplemental issues of Powder Diffraction. Tom assumed the role of Principal Scientist and Database Manager at International Centre for Diffraction Data (ICDD) upon retirement of Cyrus Crowder last fall. Since then I have been handling the Editor-in-Chief duties for papers to be printed in 2015 while Tom finalized the papers that were published in 2014. I appreciate the assistance of Nicole Ernst Boris, our Managing Editor, Tom Blanton and the group of editors for the journal during this period.

I was very honored with the invitation to become the next EiC, particularly as the journal's first Editor-in-Chief Deane Smith was my supervisor while an undergraduate working at
Lawrence Livermore National Laboratory for several summers. Deane continued to be a mentor and friend as I became involved in many aspects of powder diffraction and served in many rolls as an ICDD member.

In the tradition of all the former Editors-in-Chief I hope to continue efforts to make this journal be of value to the wide community using powder diffraction methods whether they are laboratory X-ray, synchrotron, neutron, or electron based. Please let me know what you think are strengths of the journal and what steps might be taken to build on its strong history of serving the powder diffraction community. You can contact me by e-mail at camden.hubbard@me.com.

Camden Hubbard Editor-in-Chief 